\title{
Gebelerin Fiziksel Aktivite Düzeyleri ve Yaşam Kalitelerinin İncelenmesi
}

\section{Determination of the Physical Activity and Quality of Life in Pregnant Women}

\author{
Aslı Göker ${ }^{1 *}$, Emre Yanıkkerem² ${ }^{2}$ Özge Topsakal ${ }^{2}$ \\ ${ }^{1}$ Manisa Celal Bayar Üniversitesi, Kadın Hastalıkları ve Doğum Anabilim Dalı, Manisa, Türkiye \\ ${ }^{2}$ Manisa Celal Bayar Üniversitesi, Sağlık Bilimleri Fakültesi Doğum ve Kadın Hastalıkları Hemşireliği, Manisa, \\ Türkiye
}

e-mail: asligoker@gmail.com,emrenurse@hotmail.com,ozgebydr_19@hotmail.com

ORCID: 0000-0001-8168-2610

ORCID: 0000-0001-8909-3597

ORCID: 0000-0003-2443-6397

*Sorumlu yazar/ Corresponding Author: Aslı Göker

Gönderim Tarihi / Received: 18.11.2020

Kabul Tarihi / Accepted: 06.04.2021

DOI: $10.34087 /$ cbusbed. 827769

\section{$\ddot{\mathbf{O} z}$}

Giriş ve Amaç: $\mathrm{Bu}$ çalışmada gebe kadınların fiziksel aktivite düzeyleri ve yaşam kalitelerinin incelenmesi amaçlanmıştır.

Gereç ve Yöntemler: Kesitsel olarak planlanan bu çalışma, Manisa Celal Bayar Üniversitesi Hafsa Sultan Hastanesi Kadın Hastalıkları ve Doğum Kliniği Gebe Polikliniği’ne başvuran ve son trimesterinde olan 190 gebe ile 1 Ocak- 31 Aralık 2018 tarihleri arasında gerçekleştirilmiştir. Araştırma verilerinin toplanmasında gebelerin tanıtıcı özellikleri soru formu, "Gebelik Fiziksel Aktivite Anketi (GFAA)" ve "SF-36 Yaşam Kalitesi Ölçeği (SF-36)” kullanılmıştır.

Bulgular: Gebelerin fiziksel aktivite toplam puan ortancası 110,7 metabolik eşdeğer (MET)-saat/hafta (min=23,7 maks=372,4) bulunmuştur. Kadınlar en çok ev işi/bakım (ortanca: 50,8 MET-saat/hafta) işleri olmak üzere hafif şiddette aktiviteler yaptıklarını (ortanca: 53,13 MET-saat/hafta) ifade etmişlerdir. GFAA toplam puanı ile SF-36 yaşam kalitesi ölçeği fiziksel fonksiyon ( $p=0,03)$, emosyonel rol güçlüğü $(p=0,005)$ ve mental sağlı puanı $(p=0,046)$ arasında pozitif yönde istatistiksel olarak anlamlı bir ilişki saptanmıştır.

Sonuç: Bu çalışmanın sonuçlarına göre, fiziksel aktivitenin yaşam kalitesini olumlu etkilediği bulunmuş olup sağlıklı kadınların gebelikleri sırasında fiziksel olarak aktif olmalarına yardımcı olacak girişimlerin planlanmasına gereksinim olduğu belirlenmiştir.

Anahtar kelimeler: Fiziksel aktivite, Gebelik, Yaşam kalitesi.

\section{Abstract}

Objective: The aim of the study was to determine the physical activity and quality of life in pregnant women.

Materials and Methods: The study was performed as cross sectional type with 190 last trimester pregnant women who applied to Pregnancy Clinic of Hafsa Sultan Hospital of Manisa Celal Bayar University between 1st January and 31 December 2018. The pregnant women's characteristics form, "Pregnancy Physical Activity Questionnaire (PPAQ)" and "SF-36 Quality of Life Scale were used for data collection.

Results: The median physical activity score of the pregnant women was 110.7 metabolic equivalents of task (MET) minutes per week $(\min =23.7 \mathrm{max}=372.4)$. Women reported participating in mostly light intensity (median: 53,13 MET-hr/week) activity in the form of household/caregiving (median 50.8 MET-hr-week). There was a positive statistically significant relation between PPAQ total score and SF-36 physical functioning, $(\mathrm{p}=0.03)$, emotional role difficulty $(\mathrm{p}=0.005)$ and mental health scores $(\mathrm{p}=0.046)$.

Conclusion: According to the results of this study, it was found that physical activity positively affects the quality of life, and it was determined that interventions that would help healthy women to be physically active during pregnancy were required to be planned.

Keywords: Physical activity, Pregnancy, Quality of life. 


\section{Giriş}

Günümüzde bireylerin fiziksel aktivite konusunda bilgi seviyesinin yetersiz olması, fiziksel aktivitenin sağlık için öneminin yeterince anlaşılamaması ve hareketsiz yaşam tarzının benimsenmesi obezite, kalp-damar hastalıkları, hipertansiyon, diyabet, osteoporoz gibi toplum sağlığ 1 sorunlarının görülme siklığını arttırmaktadır [1]. Dünya genelinde fiziksel inaktivite oranı kadınlarda $(\% 23,7)$, erkeklere göre $(\% 18,9)$ daha yüksek olduğu belirtilmekle birlikte gebelik süresince kadınlarda aktivitenin azaldığı belirtilmektedir [2].

Literatürde fiziksel aktivitenin sağlık açısından kanıtlanan pek çok olumlu etkisi belirtilmesine rağmen, gebe kadınlarda fiziksel aktivitenin yetersiz düzeyde olduğu belirtilmektedir. Çalışmalar gebelik trimesterlerine göre değişmekle birlikte kadınların fiziksel aktivite düzeylerinin azaldığını vurgulamaktadır $[1,3,4]$. Gebelik döneminde meydana gelen hormonal ve fiziksel değişimler gebenin fonksiyonel ve ruhsal durumunu etkileyerek yaşam kalitesinde bazı değişikliklere neden olabilmektedir. Gebelik döneminde kilo alımı, yorgunluk, uyku bozukluğu gibi fiziksel sorunların ve duygusal değișimlerin fiziksel aktivite kısıtlılığına, genel yaşam kalitesinde azalmaya neden olduğu ve bu azalmanın gebeliğin ilerleyen dönemlerinde arttığı belirtilmektedir $[5,6]$.

Gebelik döneminde fiziksel aktivitede bulunan kadınlarda maternal, fetal ve neonatal olumsuz sonuçların azaldığı, bununla birlikte anne ve çocuk sağlığının olumlu olarak da etkilendiği vurgulanmaktadır [7]. Yapılan çalışmalarda gebelikte yapılan fiziksel aktivitenin kilo kontrolü sağlamadığı belirtilmekle birlikte [8], gestasyonel diyabet $[9,10,11,12]$ ve hipertansiyon riskini azalttığı, bel ağrısı $[13,14]$ ve depresyon belirtilerini hafiflettiği, kadının ruh sağlığında iyileşme sağladığı ve yaşam kalitesini artırdığ bulunmuştur [13,15].

Amerika Birleşik Devletleri Sağlık ve Sosyal Hizmetler Bakanlığı tarafindan 2008 yılında yayımlanan Amerikalılar için Fiziksel Aktivite Rehberi'nde gebelik ve postpartum döneminde bulunan kadınlar için haftada en az 150 dakika orta seviyede fiziksel aktivite (tempolu yürüyüşe eşdeğer) önerilmiştir. Amerikan Obstetrisyenler ve Jinekologlar Birliği de komplike gebeliği olmayan kadınlara 20. gebelik haftasından sonra temas sporları ve sirtüstü pozisyon aktiviteleri gibi faaliyetlerden kaçınmak şartıyla düzenli fiziksel aktivite yapmalarını önermektedir [7].

Ülkemizde de gebe kadınların gebelik dönemi egzersizleri hakkında yeterli bilgiye sahip olmamaları ve gebelikte egzersiz yapılma oranın düşük olması dikkat çekmektedir $[9,15]$. Bu nedenle bu çalışma gebeliğe özgü bir fiziksel aktivite anketi kullanılarak gebe kadınların fiziksel aktivite düzeyleri ve yaşam kalitelerinin belirlenmesi amaciyla kesitsel ve tanımlayıcı tipte planlanmıştır.

\section{Materyal ve Metot}

\subsection{Araştırmanın Tipi ve Yeri}

Kesitsel olarak planlanan bu çalışma, Manisa Celal Bayar Üniversitesi Hafsa Sultan Hastanesi Kadın Hastalıkları ve Doğum Kliniği Gebe Polikliniği’ne başvuran gebelerde 1 Ocak- 31 Aralık 2018 tarihleri arasında gerçekleştirilmiştir.

\subsection{Araştırmanın Evren ve Örneklemi}

Araştırmanın evrenini Manisa Celal Bayar Üniversitesi Hafsa Sultan Hastanesi Kadın Hastalıkları ve Doğum Kliniği Gebe Polikliniği’ne 1 Ocak 2017 -31 Mayıs 2017 tarihleri arasında başvuran ve doğum yapmış 380 kadın oluşturmuştur. Araştırmanın örneklemi EPI Info 2000 programı ile evreni bilinen formül kullanılarak $\% 95$ güven aralığı, $\% 5$ sapma ve bilinmeyen prevelans $\% 50$ alınarak en küçük örneklem sayısı 192 olarak hesaplanmıştır. Çalışmaya 18 yaşın üzerinde, sağlıklı ve tek gebeliği olan, araştırmaya katılmak isteyen, Türkçe bilen ve 28. gebelik haftası ve üzerinde olan kadınlar dahil edilmiştir. Diyabet $(n=5)$, hipertansiyon $(n=11)$, kardiyorespiratuar hastalık $(\mathrm{n}=1)$, kronik böbrek hastalığ $(n=1)$ gibi kronik hastalıklara sahip olan, psikiyatrik açıdan bir hastalığı bulunan $(n=2)$ ve günlük işleri kısıtlayıcı şekilde kas-iskelet sistemi hastalığı olan gebeler $(\mathrm{n}=1)$ araştırmadan dışlanmıştır. Araştırma 190 kadın ile tamamlanmıştır.

\subsection{Veri Toplama Araçları}

Veri toplama formu üç bölümden oluşmaktadır. Birinci bölümde araştırmacılar tarafından geliştirilmiş gebelerin sosyo demografik özelliklerini içeren 31 soruluk "Gebelerin Tanıtıcı Özellikleri Soru Formu', kullanılmıştır. İkinci bölümde 2004 yılında ChasanTaber ve arkadaşları tarafından geliştirilen [16], Türkçe geçerlik ve güvenirliği Çırak ve arkadaşları tarafından yapilan [17] gebelerin fiziksel aktivite ve egzersiz yapma düzeylerini belirleyen ve 35 sorudan oluşan "Gebelik Fiziksel Aktivite Anketi (GFAA)', kullanılmıştır. Bu ölçek ile gebe kadınların yaptıkları ev işleri ve bakım aktiviteleri $(n=13)$, meslekle ilgili aktiviteler $(n=5)$, spor ve egzersiz aktiviteleri $(n=8)$, ulaşım $(n=3)$ ve hareketsiz yaşam $(n=3)$ olmak üzere 32 aktivite değerlendirilmektedir. Ölçekte yapılan fiziksel aktivitenin yoğunluğu MET (metabolik eşdeğer) olarak ifade edilmektedir. Aktivitelerin haftalık enerji harcamaları hesaplanırken her bir aktivite için harcanan zaman ve aktivitenin MET değeri çarpılarak puanlar haftada MET saat (MET-saat/hafta) olarak ifade edilmektedir. MET değerleri aktivite türüne göre değişmekte olup ölçek yönergesinde yer almaktadır. Açık uçlu sorularda aktivitenin MET değeri Compendium'a bakılarak belirlenmektedir [18]. Aktivite yoğunlukları sedanter $(<1,5$ METs), hafif $(1,5-3,0$ METs), orta (3,0-6,0 METs) ve şiddetli ( $>0,6$ METs) olarak gruplandırılmıştır. Aktivite tipleri ise ev işleri/bakıcılık aktiviteleri, meslekle ilgili aktiviteler ve spor/egzersiz olarak sınıflandırılmaktadır. Türkçe geçerlilik ve güvenirlik çalışmasında sınıf içi korelasyon katsayısı toplam puan için 0,95 bulunmuştur $[16,17]$. Araştırmanın üçüncü bölümünde SF-36 Yaşam Kalitesi Ölçeği kullanılmıştır. Ölçek Ware ve Sherbourne tarafından 1992 yılında geliştirilmiş ve kullanıma sunulmuştur [19]. Koçyiğit ve arkadaşları tarafından 
1999 yılında bu ölçeğin Türkçe geçerlilik çalışması yapılmıştır. $\mathrm{Bu}$ ölçek fiziksel fonksiyon, fiziksel rol güçlüğü, emosyonel rol güçlüğü, enerji, sosyal fonksiyon, ağrı, mental sağlık ve sağlığın genel olarak algılanmasına yönelik sekiz alt boyut içermekte ve her alt ölçek için ayrı ayrı skor elde edilmekte, skorların artması yaşam kalitesinde iyiliği göstermektedir.Ölçekte yer alan dördüncü ve beşinci sorular evethayır, diğer sorular likert tipi (3'lü, 5'li, 6'lı) derecelendirme ile değerlendirilmektedir. Ölçeğin 1, 6, 7, 8, 9a, 9d, 9e, 9h, $11 \mathrm{~b}, 11 \mathrm{~d}$ maddeleri ters çevrilerek puanı hesaplanmaktadır. Türkçe geçerlilik ve güvenirlik çalışmasında alt ölçeklerinin Cronbach alfa değerleri 0,73-0,76 arasında bulunmuştur [20].

\subsection{Veri Toplama Yöntemi}

Çalışmanın amacı araştırmacılar tarafından kadınlara açıklanmış ve veriler araştırmaya katılmayı kabul eden 190 kadın ile yüz yüze görüşme tekniği kullanılarak hastanede boş bir odada toplanmıștır. Verilerin toplanması yaklaşık olarak 25-30 dakika sürmüştür.

\subsection{Araştırmanın Etiğ $i$}

$\mathrm{Bu}$ çalışmanın yürütülebilmesi için Manisa Celal Bayar Üniversitesi Tıp Fakültesi Sağlık Bilimleri Etik Kurulu'ndan onay alınmıştır (tarih: 20/12/2017, say1: 57988). Araştırmaya katılan kadınlardan yazılı bilgilendirilmiş onam alınmıștır. GFAA'nin araştırmada kullanımı için Doç.Dr. Yasemin ÇIRAK'tan ve SF-36 Yaşam Kalitesi Ölçeği'nin kullanımı için Prof. Dr. Ömer AYDEMİR'den e-mail ile izin alınmıştır.

\subsection{Istatistiksel Analiz}

Verilerin analizinde SPSS $(15,0)$ programı kullanılmıştır. Verileri çözümlemede tanımlayıcı özellikler sayı, yüzde, ortanca, IQR (Interquartile Range- çeyrekler arası fark), çeyrekler arası genişlik ve minimum-maksimum değerler olarak sunulmuştur. Sürekli değişkenlerin normallik varsayımını sağlama durumu Kolmogorov-Smirnov ve Shapiro-Wilk testleri ile değerlendirilmiş, verilerin normal dağılmamasından dolayı GFAA anketi ile SF-36 arasındaki ilişki Spearman Korelasyon Analizi ile değerlendirilmiştir. Korelasyona ait güç zayıf (rho = $0,00-0,24)$, orta (rho $=0,25-0,49)$, güçlü $($ rho $=0,50-0,74)$ ve çok güçlü $(\mathrm{rho}=0,75-1,00)$ olacak şekilde sınıflandırılmıștır.

\section{Bulgular ve Tartışma \\ 3.1 Bulgular}

\subsubsection{Kadınların Tanıtıcı Özellikleri}

$\mathrm{Bu}$ araştırmada kadınların yaş ortalaması 27,8 45,1 (1843) olup, \%32,6's1 ortaokul mezunu \%22,1'i çalışmakta büyük çoğunluğunun $(\% 94,7)$ sağlık güvencesi bulunmakta ve \%69,5'i il merkezinde yaşamaktadır. Kadınların eşlerinin \%38,4'ünün lise mezunu olduğu, \%7,4'ünün çalışmadığı belirlenmiştir. Kadınların $\% 68,9$ 'u aile gelirinin giderine eşit olduğunu ifade etmiş ve $\% 12,6$ 'sı geniş aile tipinde yaşamaktadır. Evde

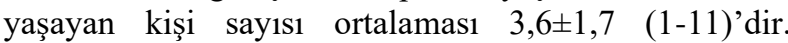
Kadınların evlilik süresi ortalaması 6,5 44,7 (1-28)'dir.

Kadınların doğurganlık özellikleri incelendiğinde \%28,4'ünün ilk gebeliğe sahip olduğu, \%31,6'sinın bir kez canlı doğum yaptığı, \%32,6’sının bir çocuğa sahip olduğu, \%3,7'sinin ölü doğum, \%7,4'ünün küretaj ve \%26,8'inin düşük öyküsü olduğu saptanmıștır. Bu çalışmada katılımcıların canlı doğum sayısı ortalaması

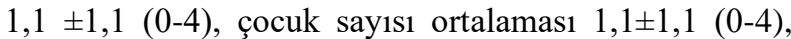
gebelik haftası ortalaması $35,6 \pm 3,0 \quad(28-42)$ 'dır. Gebelerin \%8,4'ü sigara içtiğini belirtmiş, \%12,1'i istemeden gebe kalmıştır. Kadınların büyük çoğunluğu $(\% 94,7)$ gebelik döneminde düzenli doktor kontrolüne gittiğini belirtmiştir. Kadınların \%47,9'u normal beden kitle endeksine sahip olup beden kitle indeksi ortalaması $25,0 \pm 5,2 \quad(15,3-47,8)$ olarak bulunmuștur. Gebelerin gebelik dönemindeki kilo ortalaması 77,0 $\pm 12,8$ (46-115) kg'dır (Tablo 1).

Yaklaşık on gebeden biri $(\% 11,6)$ gebelikte egzersizle ilgili bilgi aldığını belirtmiștir. Gebelikte egzersiz ile ilgili bilgi kaynakları sirasıyla doktor $(n=13, \% 56,5)$, sağlık ocağ $(n=5, \% 21.7)$, internet $(n=2, \% 8,7)$, hemşire $(\mathrm{n}=1, \% 4,3)$, spor salonu $(\mathrm{n}=1, \% 4,3)$ ve diyetisyendir $(\mathrm{n}=1, \% 4,3)$ (Veriler tabloda gösterilmemiştir).

Kadınların \%13,7'si gebelik öncesi spor yaptığını belirtmiştir. Gebelik öncesi yapılan spor türleri incelendiğinde; kadınların büyük çoğunluğu $(n=18$, $\% 69,2$ ) yürüyüş yapmaktadır. Yapılan diğer spor türleri ise tempolu yürüyüş $(n=4, \% 15,4)$, plates $(n=2, \% 7,7)$, bisiklet $(\mathrm{n}=1, \% 3,8)$ ve voleyboldur $(\mathrm{n}=1, \% 3,8)$ (Veriler tabloda gösterilmemiştir).

Gebelik döneminde spor yaptığını belirten kadınların oranı $\% 13,7$ olarak saptanmıştır. Gebelikte yapılan spor türleri yürüyüş $(n=25, \% 96,2)$ ve tempolu yürüyüştür $(\mathrm{n}=1, \% 3,8)$. Kadınların haftada yaptıkları yürüyüş dağılımı incelendiğinde, haftada $2,3,4,5$ ve 7 kez yürüyüş yapanların oranı sirasiyla \%15,4 (n=4), \%30,8 $(n=8)$, $\% 11,5(n=3), \% 3,8(n=1)$ ve $\% 38,5$ 'dir $(n=10)$. Gebelikte yapılan yürüyüş ortalaması haftada $4,6 \pm 2,1 \mathrm{kez}$, $38,3 \pm 18,1$ dakika bulunmuştur (Veriler tabloda gösterilmemiştir).

Gebeliğin ilk, ikinci ve son üç ayında spor yaptığını belirten kadınların oranı sirasiyla $\% 6,8, \% 10,5$ ve $\% 10,5$ olup spor yapan gebelerin tamamı yürüyüş yapmıştır. Gebeliğin ilk üç ayında spor yapan gebelerin yürüyüş ortalamas1 haftada $3,8 \pm 2,2 \mathrm{kez}$ ve $43,3 \pm 17,8$ dakika olarak bulunmuştur. Gebeliğin ikinci üç ayında yürüyüş ortalamas1 haftada $4,4 \pm 2,1 \mathrm{kez}$ ve $41,8 \pm 18,1$ dakika olarak belirlenmiştir. Gebeliğin son üç ayında yürüyüş ortalamas1 haftada 4,2 $\pm 2,2 \mathrm{kez}$ ve $39,8 \pm 16,4$ dakikadır (Veriler tabloda gösterilmemiştir).

3.1.2. Gebelerin Tanımlayıcı Özellikleri, Gebelik Fiziksel Aktivite Anketi Ve SF-36 Yaşam Kalitesi Ölçeği Puanları Gebelerin tanımlayıcı özellikleri, GFAA ve SF-36 Yaşam Kalitesi Ölçeği puanları Tablo 2'de gösterilmiştir. Gebelerin fiziksel aktivite toplam puan ortancası 110,7 MET-saat/hafta $(\mathrm{min}=23,7$ maks $=372,4)$ bulunmuştur. $\mathrm{Bu}$ çalışmada kadınların en çok hafif şiddette aktiviteler yaptıkları (ortanca: 53,13 MET-saat/hafta) ve en çok ev işi/bakım (ortanca: 50,8 MET-saat/hafta) işleriyle uğraştıkları saptanmıştır.

Araştırmaya katılan gebelerin SF-36 Yaşam Kalitesi Ölçeği alt ölçek puan ortancaları sosyal fonksiyon için 62,5 mental sağl1k ve genel sağlık alg1sı için 60 olarak saptanmıştır (Tablo 2). 
Tablo 1. Gebelerin Tanıtıcı Özellikleri

\begin{tabular}{|c|c|c|c|c|c|}
\hline Özellikler & $\mathbf{n}$ & $\%$ & & $\mathbf{n}$ & $\%$ \\
\hline Kadının yaş ortalaması $27,8 \pm$ & \multicolumn{2}{|c|}{$27,8 \pm 5,1(18-43)$} & Eşin yaş ortalaması & \multicolumn{2}{|c|}{$31,5 \pm 5,1(18-50)$} \\
\hline \multicolumn{3}{|c|}{ Kadının eğitim durumu } & Eşin eğitim durumu & & \\
\hline Okuryazar değil+okuryazar & 15 & 7,9 & Okuryazar değil+okuryazar & 6 & 3,2 \\
\hline İlkokul & 41 & 21,6 & İlkokul & 36 & 18,9 \\
\hline Ortaokul & 62 & 32,6 & Ortaokul & 45 & 23,7 \\
\hline Lise & 39 & 20,5 & Lise & 73 & 38,4 \\
\hline Üniversite & 33 & 17,4 & Üniversite & 30 & 15,8 \\
\hline \multicolumn{3}{|l|}{ Kadının çalışma durumu } & Eşin çalışma durumu & & \\
\hline Çalışan & 42 & 22,1 & Çalışan & 176 & 92,6 \\
\hline Çalışmayan & 148 & 77,9 & Çalışmayan & 14 & 7,4 \\
\hline \multicolumn{3}{|l|}{ Sağlık güvencesi } & Aile tipi & & \\
\hline Var & 180 & 94,7 & Geniş & 24 & 12,6 \\
\hline Yok & 10 & 5,3 & Çekirdek & 166 & 87,4 \\
\hline \multicolumn{3}{|l|}{ Yaşanılan yer } & Ailenin gelir gider durumu & & \\
\hline İl & 132 & 69,5 & Gelir giderden az & 40 & 21,1 \\
\hline İlçe & 44 & 23,2 & Gelir gidere eşit & 131 & 68,9 \\
\hline Köy & 14 & 7,4 & Gelir giderden fazla & 19 & 10,0 \\
\hline \multicolumn{6}{|l|}{ Gebelik sayısı } \\
\hline 1 & 54 & 28,4 & Gebelikte egzersiz ile ilgili & & \\
\hline 2 & 45 & 23,7 & bilgi alma durumu & & \\
\hline 3 & 44 & 23,2 & Evet & 22 & 11,6 \\
\hline 4 ve üzeri & 47 & 24,7 & Hayır & 168 & 88,4 \\
\hline \multicolumn{3}{|l|}{ Canlı doğum sayısı } & Kadının gebelik öncesi spor & & \\
\hline 0 & 67 & 35,3 & yapma durumu & 26 & 13,7 \\
\hline 1 & 60 & 31,6 & Evet & 164 & 86,3 \\
\hline 2 & 44 & 23,2 & Hayır & & \\
\hline 3 ve üzeri & 19 & 10,0 & & & \\
\hline \multicolumn{3}{|l|}{ Çocuk sayısı } & Kadının gebelikte spor yapma & & \\
\hline Çocuk yok & 65 & 34,2 & durumu & & \\
\hline 1 çocuk & 62 & 32,6 & Evet & 26 & 13,7 \\
\hline 2 çocuk & 44 & 23,2 & Hayır & 164 & 86,3 \\
\hline 3 ve üzeri & 19 & 10,0 & & & \\
\hline \multicolumn{3}{|l|}{ Ölü doğum } & $\begin{array}{l}\text { Gebeliğin ilk üç ayında spor } \\
\text { yapma durumu }\end{array}$ & & \\
\hline Yok & 183 & 96,3 & Evet & 13 & 6,8 \\
\hline Var & 7 & 3,7 & Hayır & 177 & 93,2 \\
\hline \multicolumn{3}{|l|}{ Küretaj } & $\begin{array}{l}\text { Gebeliğin ikinci üç ayında } \\
\text { spor yapma durumu }\end{array}$ & & \\
\hline Yok & 176 & 92,6 & Evet & 20 & 10,5 \\
\hline Var & 14 & 7,4 & Hayır & 170 & 89,5 \\
\hline \multicolumn{3}{|l|}{ Düşük } & $\begin{array}{l}\text { Gebeliğin son üç ayında spor } \\
\text { yapma durumu }\end{array}$ & & \\
\hline Yok & 139 & 73,2 & Evet & 20 & 10,5 \\
\hline Var & 51 & 26,8 & Hayır & 170 & 89,5 \\
\hline \multicolumn{3}{|l|}{ Kadının sigara içme durumu } & Düzenli doktor kontrollerine & & \\
\hline Evet & 16 & 8,4 & gitme durumu & & \\
\hline \multirow[t]{2}{*}{ Hayır } & 174 & 91,6 & Evet & 180 & 94,7 \\
\hline & & & Hayır & 10 & 5,3 \\
\hline \multirow{5}{*}{$\begin{array}{l}\text { İsteyerek gebe kalma durumu } \\
\text { Evet } \\
\text { Hayır }\end{array}$} & \multirow{5}{*}{$\begin{array}{l}167 \\
23\end{array}$} & \multirow{5}{*}{$\begin{array}{l}87,9 \\
12,1\end{array}$} & $\begin{array}{l}\text { Kadının gebelik öncesi beden } \\
\text { kitle indeksi }\end{array}$ & & \\
\hline & & & $<18.5 \mathrm{~kg} / \mathrm{m}^{2}$ (zayif) & 15 & 7,9 \\
\hline & & & $18.5-24.9 \mathrm{~kg} / \mathrm{m}^{2}$ (normal ) & 91 & 47,9 \\
\hline & & & $25-29.9 \mathrm{~kg} / \mathrm{m}^{2}$ (fazla kilolu) & 54 & 28,4 \\
\hline & & & $30-39.9 \mathrm{~kg} / \mathrm{m}^{2}(\mathrm{obez})$ & 30 & 15,8 \\
\hline
\end{tabular}


Tablo 2. Gebelerin Tanımlayıcı Özellikleri, Gebelik Fiziksel Aktivite Anketi ve SF-36 Yaşam Kalitesi Ölçeği puanlar1

\begin{tabular}{|c|c|c|c|}
\hline & Ortanca (IQR) & $\begin{array}{l}\text { Minimum- } \\
\text { Maksimum }\end{array}$ & Çeyrekler arası aralık \\
\hline Yaş (yıl) & $27(8)$ & $18-43$ & $24-32$ \\
\hline BKİ & $24,2(7,3)$ & $15,37-47,87$ & $21,32-28,63$ \\
\hline Gebelikte kilo alımı & $11(7)$ & $(-5)-30$ & $8-15$ \\
\hline Doğum sayıs1 & $1(2)$ & $0-4$ & $0-2$ \\
\hline Küretaj sayıs1 & $0(0)$ & $0-2$ & $0-0$ \\
\hline Düşük sayısı & $0(1)$ & $0-4$ & $0-1$ \\
\hline Gebelik haftası & $36(4)$ & $28-42$ & $34-38$ \\
\hline \multicolumn{4}{|c|}{ Gebelik Fiziksel Aktivite Anketi (GFAA) } \\
\hline Total aktivite & $110,7(65,9)$ & $23,7-372,4$ & $83,20-149,05$ \\
\hline \multicolumn{4}{|l|}{ Aktivite şiddeti } \\
\hline Sedanter $(<1,5$ METs $)$ & $31,85(28,4)$ & $0-140,2$ & $18,5-46,9$ \\
\hline Hafif aktivite $(1,5-<3,0 \mathrm{METs})$ & $53,13(46,1)$ & $8,6-125,9$ & $37,1-83,2$ \\
\hline Orta aktivite $(3,0-6,0 \mathrm{METs})$ & $15,8(20,7)$ & $7-160,2$ & $9,01-29,8$ \\
\hline Şiddetli aktivite $(>6,0 \mathrm{METs})$ & $0(0)$ & $0-7$ & $0-0$ \\
\hline \multicolumn{4}{|l|}{ Tipi } \\
\hline Ev işi/bakım aktiviteleri & $50,8(29,8)$ & $20,9-126,6$ & $38,4-68,2$ \\
\hline İş meslek aktiviteleri & $0(0)$ & $0-289,97$ & $0-0$ \\
\hline Egzersiz spor aktiviteleri & $0,38(2,2)$ & $0-21,1$ & $0-2,2$ \\
\hline \multicolumn{4}{|c|}{ SF-36 Yaşam Kalitesi Ölçeği Alt Boyutları } \\
\hline Fiziksel Fonksiyon & $50(30)$ & $0-100$ & $35-65$ \\
\hline Fiziksel Rol Güçlüğü & $12,9(50)$ & $0-100$ & $0-50$ \\
\hline Ağr1 & $57,5(33,13)$ & $0-100$ & $42,5-75,6$ \\
\hline Genel Sağlık Algısı & $60(25,0)$ & $20-100$ & $50-75$ \\
\hline Enerji & $36,3(16,8)$ & $5,5-71,5$ & $29,3-46$ \\
\hline Sosyal Fonksiyon & $62,5(37,5)$ & $12,5-100$ & $50-87,5$ \\
\hline Emosyonel Rol Güçlüğü & $33,3(100)$ & $0-100$ & $0-100$ \\
\hline Mental Sağlık & $60(24)$ & $16-96$ & $48-72$ \\
\hline
\end{tabular}


3.1.3. Kadınların Gebelik Fiziksel Aktivite Anketi ve SF36 Yaşam Kalitesi Ölçeğinden Aldıkları Puanlar Arasındaki İlişki

GFAA toplam aktivite puanı ile SF-36 yaşam kalitesi ölçeği fiziksel fonksiyon $(\mathrm{p}=0,03)$, emosyonel rol güçlüğü $(p=0,005)$ ve mental sağlık puanı $(p=0,046)$ arasında pozitif yönde zayıf düzeyde anlamlı bir ilişki saptanmıştır. Hafif aktivite ile emosyonel rol güçlüğü $(p=0,005)$ ve sosyal fonksiyon $(p=0,044)$ arasında pozitif yönde zayıf düzeyde anlamlı bir ilişki belirlenmiştir. Orta şiddetli aktivite puanı ile fiziksel fonksiyon puanı $(\mathrm{p}=0,000)$ arasında pozitif yönde orta düzeyde enerji puanı $(p=0,035)$ ile arasında pozitif yönde zayıf düzeyde anlamlı bir ilişki bulunmuştur. Şiddetli aktivite ile fiziksel fonksiyon puanı $(p=0,002)$ ve iş meslek aktiviteleri ile emosyonel rol güçlüğü $(p=0,023)$ puanı arasında pozitif yönde zayıf düzeyde anlamlı bir ilişki saptanmıştır. Ev işi/bakım aktiviteleri ile sosyal fonksiyon puanı arasında pozitif yönde zayıf düzeyde anlamlı bir ilişki saptanmıştır $(p=0,010)$. Egzersiz spor aktiviteleri puanı ile fiziksel fonksiyon puanı $(p=0,00)$ arasında pozitif yönde orta düzeyde, ağrı puanı $(p=0,05)$ ve genel sağlık algısı puanı $(\mathrm{p}=0,002)$ ile pozitif yönde zayıf düzeyde anlamlı bir ilişki saptanmıştır (Tablo 3).

Tablo 3. Gebelikte Fiziksel Aktivite Anketi ve SF-36 Yaşam Kalitesi Ölçeği Arasındaki İlişki

\begin{tabular}{|c|c|c|c|c|c|c|c|c|c|}
\hline & & $\begin{array}{l}\text { Total } \\
\text { aktivite }\end{array}$ & $\begin{array}{l}\text { Sedante } \\
\mathbf{r}\end{array}$ & $\begin{array}{l}\text { Hafif } \\
\text { aktivite }\end{array}$ & $\begin{array}{l}\text { Orta } \\
\text { aktivite }\end{array}$ & $\begin{array}{l}\text { Şiddetli } \\
\text { aktivite }\end{array}$ & $\begin{array}{l}\text { Ev işi/bakım } \\
\text { aktiviteleri }\end{array}$ & $\begin{array}{l}\text { İş meslek } \\
\text { aktiviteler } \\
\text { i }\end{array}$ & $\begin{array}{l}\text { Egzersiz } \\
\text { spor } \\
\text { aktivitel } \\
\text { eri }\end{array}$ \\
\hline Fiziksel & $\mathrm{r}$ & ,157 &,- 076 &, 117 & 260 & ,226 & ,046 & ,108 & ,296 \\
\hline Fonksiyon & $\mathrm{p}$ &, $\mathbf{0 3 0}$ & ,296 & ,108 & ,000 &, 002 &, 533 &, 138 & ,000 \\
\hline Fiziksel Rol & $\mathrm{r}$ & ,103 &, 044 & ,107 &,- 004 & ,036 & 039 & ,112 & ,009 \\
\hline Güçlüğü & $\mathrm{p}$ &, 158 &, 544 & ,141 & ,954 & ,619 &, 593 &, 123 & ,906 \\
\hline Emosyonel & $\mathrm{r}$ & ,201 & ,037 & ,205 & ,006 &,- 077 & ,076 &, 165 &,- 014 \\
\hline Rol Güçlüğü & $\mathrm{p}$ &, 005 & ,617 &, 005 & ,932 & ,293 & ,294 &, 023 & ,844 \\
\hline Ăgrı & $\mathrm{r}$ & ,029 &,- 039 &, 081 & ,007 &, 124 & ,096 & ,003 & ,143 \\
\hline & $\mathrm{p}$ & ,694 &, 589 & ,264 & ,921 &, 088 & ,189 & ,969 & ,050 \\
\hline Genel Sağlık & $\mathrm{r}$ &, 141 & ,090 &, 111 & ,096 & ,069 & ,049 & ,096 & ,224 \\
\hline Algisı & $\mathrm{p}$ & ,053 & ,216 & ,127 &, 188 &, 347 & ,498 & ,186 & ,002 \\
\hline Enerji & $\mathrm{r}$ &, 021 &,- 025 &,- 028 &, 153 &, 018 & 075 &,- 021 &,- 014 \\
\hline & $\mathrm{p}$ & ,773 &, 735 & ,701 & ,035 & ,807 & ,301 &, 769 & ,845 \\
\hline Mental & $\mathrm{r}$ &, 145 &, 066 & ,108 &, 102 &,- 084 & ,090 &,- 013 & ,020 \\
\hline Nagim & $\mathrm{p}$ & ,046 & ,366 & ,139 &, 160 &, 250 & ,216 &, 858 & ,788 \\
\hline Sosyal & $\mathrm{r}$ &, 127 &, 114 &, 146 & ,002 &,- 067 & ,188 & ,005 &,- 010 \\
\hline Fonksiyon & $\mathrm{p}$ &, 080 & ,116 & ,044 & ,982 & ,360 & ,010 & ,943 & ,896 \\
\hline
\end{tabular}




\subsection{Tartışma}

$\mathrm{Bu}$ çalışma gebelerin fiziksel aktivite düzeyi ve yaşam kalitelerini değerlendirmek amacıyla gerçekleștirilmiştir. Sağlık açısından kanıtlanan bir çok etkisi olan ve bireylerin yaşam kalitesini artıran fiziksel aktivitenin gebelik döneminde değerlendirilmesinin önemli olduğu kadar değerlendirmede kullanılan soru formları da önem taşımaktadır. Literatür incelendiğinde yurtdışında gebelere özgü geliştirilmiş olan GFAA kullanılarak yapılmış araştırmaların olduğu görülmektedir [3,12,21,22,23]. Türkiye'de GFAA'nin geçerlik güvenirlik çalışması 2015 yılında yapılmıştır. GFAA kullanılarak gebelerin yaşam kalitesinin değerlendirildiği basılı bir çalışma bu çalışmanın planlanma aşamasında bulunamamış yazım aşamasında bir çalışmaya rastlanmıştır. $\mathrm{Bu}$ nedenle araştırmanın gebelere özgü geliştirilmiş ve kullanımı yeni olan bu ölçekle yapılması literatüre katk1 vermesi nedeniyle önemlidir.

Çalışmamızda gebelerin çok az bir kısmı $(\% 11,6)$ gebelikte egzersizle ilgili bilgi aldığını belirtmiş olup bilgi kaynağı olarak ilk sırada doktor olmak üzere, sağlık ocağ1, internet, hemşire, spor salonu ve diyetsiyen olduğu görülmektedir. Ege Bölgesi'nde yapılan bir çalışmada gebelerin \%27,9'u gebelik egzersizleri hakk11nda bilgi sahibi olduklarını belirtmiş, bu gebelerin yarısı bilgi kaynağı olarak sağlık personelini göstermiştir [9] Karaman'da yapılan bir çalışmada gebelerin \%61,1'inin gebelik egzersizleri hakkında bilgi sahibi oldukları egzersizler ile ilgili bilgilerin çoğunluğunun görsel ve yazılı medya ile $(\% 36,3)$ elde edildiği belirlenmiştir [1] Portekiz'de yapılan bir çalıșmada kadınların üçte ikisi egzersizle ilgili bilgiyi sağlık personelinden aldığını ifade etmiştir [3]. $\mathrm{Bu}$ araştırmada kadınların gebelikte egzersizle ilgili bilgi alma durumlarının yapılan diğer çalışmalara göre oldukça düşük olduğu görülmektedir. $\mathrm{Bu}$ nedenle gebe eğitimlerinde gebelikte egzersizin faydaları ve öneminin üzerinde durulması önemlidir.

Bu çalışmada gebelik öncesi ile gebelik döneminde spor yapan kadınların oranının $(\% 13,7)$ olduğu gebelik öncesi $(\% 69,2)$ ve gebelikte $(\% 96,2)$ en çok yapılan egzersizin yürüyüş olduğu bulunmuştur. Malatya'da yapılan bir çalışmada gebelerin \%10,4'ünün [15], İzmir'de $\% 40,1$ 'inin [9] egzersiz yaptığı bulunmuştur. Gebelerin egzersiz yapma oranları bölgelere göre farklılık göstermektedir.

$\mathrm{Bu}$ araștırmada kadınların ikinci ve üçüncü trimesterde ilk trimestere göre daha fazla spor yaptıkları bulunmuştur. Tayvan'da fiziksel aktivitenin doğum şekline etkisinin araştırıldığı 150 gebe kadınla yapılan çalışmada gebe kadınların fiziksel aktivitelerinin, gebelik öncesi dönem ile karşılaştırıldığında \%31 oranında azaldığı ve genel fiziksel aktivite seviyelerinin gebelik öncesi dönem ve ilk trimesterde düşük olduğu ancak ikinci trimesterde normal seviyeye geldiği ve üçüncü trimesterde orta seviyede azaldığı tespit edilmiştir [23]. İzmir'de gebelikte fiziksel aktivite değişiminin incelendiği bir çalışmada gebelerin ikinci trimesterde birinci ve üçüncü trimestere göre fiziksel aktivite şiddetini artırdıkları saptanmıştır [24]. Gebeliğin ilk trimesteri için elde edilen bu sonuçlar gebeliğin ilk üç ayında kadınların gebeliğin devamını sağlama çabası ve gebeliğe bağlı yaşadıkları fiziksel rahatsızlıklara bağlı olabilir.

$\mathrm{Bu}$ çalışmada gebelerin fiziksel aktivite toplam puan ortancas1 110,7 MET-saat/hafta bulunmuş olup kadınların en çok hafif şiddette aktiviteler yaptıkları ve en çok ev işi/bakım işleriyle uğraştıkları saptanmıştır. Kanada'da gebelikte ideal kilo alımı ile ilişkili davranışları belirlemek amacıyla yapılan bir çalışmada gebelerin en çok sedanter aktivite yaptığ 1 bunu hafif ve orta şiddette aktivitenin izlediği ve en yaygın yapılan aktivitenin yürüyüş olduğu bulunmuştur [21]. Ege Bölgesi'nde yapılan bir çalışmada gebelerin üçüncü trimester fiziksel aktivite toplam puan ortancası ilk ve ikinci trimester puanlarından düşük olarak 131,6 METsaat/hafta bulunmuş en çok hafif yoğunluklu aktivite yaptıkları ve en çok ev işi/bakım işleriyle uğraştıkları saptanmıştır [25]. Benzer şekilde Portekiz [3] ve Çin'de [26] yapılan çalışmalarda gebelerin her üç trimesterde de en çok hafif yoğunlukta aktivite yaptıkları bulunmuştur. $\mathrm{Bu}$ araştırmada gebelerin SF-36 Yaşam Kalitesi Ölçeği'nin fiziksel rol güçlüğü, , enerji ve emosyonel rol güçlüğü alt boyutlarının puan ortancalarına göre yaşam kalitesinin orta düzeyin altında olduğu saptanmıştır. Araştırma bulgularına benzer şekilde Erzurum'da üçüncü trimesterde olan gebelerin sosyodemografik özellikleri ile yaşam kalitesinin incelendiği bir çalışmada gebelerin fiziksel rol güçlüğü, enerji ve ağrı alt boyutlarında yaşam kalitesinin orta düzeyin altında olduğu saptanmıştır [27]. Gebelerin uyku kalitesi ve yaşam kalitesinin değerlendirildiği Eskişehir'de yapılan bir çalışmada ise gebelerin ağrı ve mental sağlık dışındaki tüm alt boyutlarda yaşam kalitesinin orta düzeyin altında olduğu bulunmuştur [28]. $\mathrm{Bu}$ araştırma ve diğer çalışma sonuçlarına göre genel olarak gebelik sürecinin yaşam kalitesini olumsuz etkilediğini görülmektedir.

$\mathrm{Bu}$ çalışmada gebelerde fiziksel aktivite ile yaşam kalitesi arasındaki ilişki incelendiğinde total aktivite puanındaki artışın yaşam kalitesi alt boyutlarından fiziksel fonksiyon, emosyonel rol güçlügü ve mental sağlığı olumlu etkilediği bulunmuştur. Hafif aktivite puan artışının emosyonel rol güçlüğü ve sosyal fonksiyonu; orta aktivite puan artışının fiziksel fonksiyon ve enerji; şiddetli aktivite puan artışının fiziksel fonksiyonu olumlu etkilediği belirlenmiştir. Bununla birlikte ev işi/bakım aktivite puan artışının sosyal fonksiyonu, iş meslek aktiviteleri puan artışının emosyonel rol güçlügünü ve egzersiz spor aktiviteleri puan artışının fiziksel fonksiyonu, ağrıyı ve genel sağlık algısını olumlu etkilediği saptanmıştır. $\mathrm{Bu}$ araştırma bulgularına benzer şekilde gebelik döneminde egzersiz yapmanın gebelerin genel yaşam kalitesini olumlu etkilediğini gösteren çalışmalar bulunmaktadır $[5,6,29,30,31,32]$. Lübnan'da yapılan bir çalışmada total aktivite puanı ve hafif düzeyde yapılan fiziksel aktivitenin psikolojik sağlık ve sosyal ilişki alt boyutlarını olumlu etkileyerek gebelerin yaşam kalitesini artırdığı, spor/egzersiz türü aktivite yapmanın ise yaşam kalitesi ölçeğinin genel sağlık alt boyutu hariç diğer tüm alt boyutlarında artışa neden olduğu 
bulunmuştur [6]. Bolu'da yapılan bir çalışmada fiziksel aktivite seviyesi ile yaşam kalitesi arasında negatif yönde ilişki olduğu bulunmuştur. Bu çalışmada Uluslararası Fiziksel Aktivite Anketi-Kısa Formu kullanılmış ve gebeliğe özgü fiziksel aktivite anketi kullanılması önerilmiştir [32]. İstanbul'da genel yaşam kalitesi ölçeği kullanılarak yapılan bir çalışmada gebelerin total fiziksel aktivite seviyeleri ile yaşam kaliteleri arasında anlamlı ilişki bulunmamıştır [25]. Çalışma sonuçlarındaki farklılıklar yaşam kalitesini etkileyebilecek diğer faktörler ve araştırmalarda farklı ölçeklerin kullanılmasından kaynaklanıyor olabilir.

\section{Sonuc}

Gebelerin fiziksel aktivite düzeyi ve yaşam kalitelerinin incelendiği bu çalışmada fiziksel aktivitenin yaşam kalitesini olumlu etkilediği görülmektedir. Bununla birlikte bu çalışmada kadınların gebelik dönemi egzersizleri ile ilgili yeterli bilgi almadıkları saptanmış olup sağlıklı kadınların gebelikleri sırasında fiziksel olarak aktif olmalarına yardımcı olacak girişimlerin planlanmasının önemli olduğu düşünülmektedir.

\section{Referanslar}

1. Yalçın, H, Tekin, M, Gebelikte egzersizler hakkında gebelerin bilg düzeyinin değerlendirilmesi, International Journal of Human Science, 2013, 10(1), 24-33.

2.Dumith, S.C, Hallal, P.C, Reis, R.S, Kohl H.W 3rd, Worldwide prevalence of physical inactivity and its association with human development index in 76 countries, Preventive Medicine, 2011, 53, 24-28.

3. Santos, P.C, Abreu, S, Moreira, C, Santos, R, Ferreira, M, Alves, O, Ferreira, M, Mota, J, Physical activity patterns during pregnancy in a sample of Portuguese women: a longitudinal prospective study, Iranian Red Crescent Medical Journal, 2016, 18(3), e22455.

4. Schmidt, T, Heilmann, T, Savelsberg, L, Maass, N, Weisser, B Eckmann-Scholz, C, Physical Exercise During Pregnancy-How Active Are Pregnant Women in Germany and How Well Informed? Geburtshilfe Frauenheilkd, 2017, 77(5), 508-515.

5. Kolu, P, Raitanen, J, Luoto, R, Physical activity and health related quality of life during pregnancy: a secondary analysis of a clusterrandomised trial, Maternal and Child Health Journal, 2014,18(9), 2098-2105.

6. Mourady, D, Richa, S, Karam, R, Papazian, T, Moussa, F.H, El Osta, N., Kesrouani, A, Azouri, J, Jabbour, H, Hajj A, Khabbaz L.R, Associations between quality of life, physical activity, worry, depression and insomnia: A cross-sectional designed study in healthy pregnant women, PloS One, 2017, 12(5), e0178181.

7.Physical activity and exercise during pregnancy and the postpartum period. Committee Opinion No. 650. American College of Obstetricians and Gynecologists, Minerva Obstetrics and Gynecology, 2015;126:e135-42.

8. Rooney, B.L, Schauberger C.W, Mathiason, M.A, Impact of perinata weight change on long-term obesity and obesity-related illnesses, Obstetrics and Gynecology, 2005, 106, 1349-56.

9. Balsak, D, Yıldırım, Y, Avcı, M.E, Töz, E, Gültekin, E, Kayhan K, Yorgun S, Tınar Ç, Ege bölgesinde yaşayan gebe kadınların gebelik egzersizleri hakkındaki bilgi ve davranışlarının incelenmesi, Trakya Üniversitesi Tıp Fakültesi Dergisi, 2007, 24(3), 200-204.

10. Barakat, R, Cordero, Y, Coteron, J, Luaces, M, Montejo, R, Exercise during pregnancy improves maternal glucose screen at 24-28 weeks: a randomized controlled trial, British Journal of Sports Medicine, 2012, 46, 656-661

11. Deierlein, A.L, Siega-Riz, A.M, Evenson, K.R. Physical activity during pregnancy and the risk of hyperglycemia, Journal of Women's Health, 2012, 21, 769-775.

12. Chasan-Taber, L, Silveira, M, Lynch, K.E, Pekow, P, Braun, B, Manson J.E, Solomon C.G, Markenson, G, Physical activity before and during pregnancy and risk of abnormal glucose tolerance among Hispanic women, Diabetes \& Metabolism, 2014a, 40(1), 67-75.
13. Baykal, Z, Bel ağrisı olan gebelerde progresif gevseme egzersizlerinin ağrı algısına ve yaşam kalitesi üzerine etkisi, Ege Üniversitesi Sağlık Bilimler Enstitüsü, Yüksek Lisans Tezi.

14. Köstü, B, Kültür, T, Ercan, Ö, Bakacak, M, Gebelikte egzersizin bel ağrıları ve lordoz üzerine etkisi, Kahramanmaraş Sütçü Imam Universitesi Tip Fakültesi Dergisi, 2015, 10(1), 6-8.

15. Ünver, H, Aylaz, R, Gebelerde fiziksel egzersizin yaşam kalitesi üzerine etkisi, Türkiye Klinikleri Jinekoloji Obstetrik, 2017, 27(2),71-8

16. Chasan-Taber, L, Schmidt, M.D, Roberts, D.E, Hosmer D, Markenson G, Freedson P.S, Development and validation of a Pregnancy Physical Activity Questionnaire, Medicine and Science in Sports and Exercise, 2004, 36(10), 1750-1760.

17. Çırak, Y, Yılmaz, G.D, Demir, Y.P, Dalkılınç, M, Yaman, S, Pregnancy physical activity questionnaire (PPAQ): reliability and validity of Turkish version, Journal of Physical Therapy Science, 2015, 27(12), 3703-3709.

18. Ainsworth, B.E, Haskell, W.L, Herrmann, S.D, Meckes N, Bassett D.R, Tudor-Locke, C, Greer J.L, Vezina J, Whitt-Glover M.C, Leon A.S, 2011 Compendium of Physical Activities: a second update of codes and MET values, Medicine and Science in Sports and Exercise, 2011, 43(8), 1575-1581.

19. Ware, Jr, J.E, Sherbourne, C.D., The MOS 36-item short-form health survey (SF-36): I. Conceptual framework and item selection, Medical Care, 1992, 30(6), 473-83.

20. Koçyiğit, H, Aydemir, Ö, Ölmez, N ve ark., SF-36'nın Türkçe için güvenilirliği ve geçerliliği, İlaç ve tedavi, 1999, 12, 102-6.

21. Cohen, T.R, Plourde, H, Koski, K.G, Use of the Pregnancy Physical Activity Questionnaire (PPAQ) to identify behaviours associated with appropriate gestational weight gain during pregnancy, Journal of Physical Activity \& Health, 2013, 10(7), 1000-1007.

22. Chasan-Taber, L, Silveira, M, Lynch, K.E, Pekow, P, Solomon, C.G, Markenson, G, Physical activity and gestational weight gain in Hispanic women, Obesity, (2014b), 22(3), 909-918.

23. Ko, Y.L, Chen, CP, Lin, P.C, Physical activities during pregnancy and type of delivery in nulliparae, European Journal of Sport Science, 2016, 16(3), 374-380.

24. Tosun, Ö.Ç, Okyay, R.E, Gebelik sürecinde fiziksel aktivite değişimlerinin incelenmesi, Sağllk Bilimleri ve Meslekleri Dergisi, 2018, 5(3), 333-341

25. Kostanoğlu, A, Manzak, A.S, Sahin, A, Gebelerde Fiziksel Aktivite Seviyesi ve Uyku Kalitesinin Yaşam Kalitesine Etkisi, Türk Uyku Tlbbu Dergisi, 2019, 3, 80-87.

26. Yin, Y.N, Huang, Y, Liu, X.H, Luo, B.R, Assessment of physical activity status among pregnant women in southwestern China, Frontiers of Nursing, 2019, 6(2), 135-141.

27. Calikoglu, E.O, Akcay, H.B, Kavuncuoglu, D, Tanriverdi, E.C, Yerli, E.B, Salcan, S, Socio-demographic characteristics and quality of life among women in the 3rd trimester of pregnancy living in Erzurum city center, Aile Hekimliği ve Palyatif Bakım, 2018, 3(1), 33-38.

28. Özhüner, Y, Çelik, N, Gebelerde uyku kalitesi ve yaşam kalitesi, Sağlık Bilimleri ve Meslekleri Dergisi, 2019, 6 (1), 25-33.

29. Goodwin, A, Astbury, J, McMeeken, J, Body image and psychological well-being in pregnancy, A comparison of exercisers and non-exercisers, The Australian \& New Zealand Journal of Obstetrics \& Gynaecology, 2000, 40(4), 442-447.

30. Thorell, E, Svardsudd, K, Andersson, K, Kristiansson P, Moderate impact of full-term pregnancy on estimated peak oxygen uptake, physical activity and perceived health, Acta Obstetricia et Gynecologica Scandinavica, 2010, 89(9), 1140-1148.

31. Arizabaleta, A.V.M, Buitrago, L.O, de Plata, A.C.A, Escudero, M.M, Ramírez-Vélez, R, Aerobic exercise during pregnancy improves health-related quality of life: a randomised trial, Journal of Physiotherapy, 2010, 56(4), 253-258.

32. Özdemir, Ö.Ç, Sürmeli, M, Özel, A, Yavuz, İ.E, Topçuoğlu, A, Ankaralı, H, Gebelerde fiziksel aktivite ve yaşam kalitesi arasındaki ilişki, Anadolu Kliniği Tip Bilimleri Dergisi, 2017, 22(2) ,95-102.

http://edergi.cbu.edu.tr/ojs/index.php/cbusbed isimli yazarın CBU-SBED başlıklı eseri bu Creative Commons Alıntı-Gayriticari4.0 Uluslararası Lisansı ile lisanslanmıştır. 